\title{
TNF- $\alpha$ Regulated MAdCAM-1 Expression in Pancreatic Microvessel Endothelium: A Possible Role for MAdCAM-1 in Pancreatitis?
}

\author{
Tomoaki Ando ${ }^{1}$, Paul Jordan ${ }^{2}$, Yuping Wang ${ }_{*}^{3}$, Alireza Minagar ${ }^{4}$, Merilyn H. Jennings ${ }^{1}$, \\ Takashi Joh ${ }^{5}$ and Jonathan Steven Alexander ${ }^{*}, 1$ \\ ${ }^{I}$ Molecular and Cellular Physiology, LSU Health Sciences Center, Shreveport, Louisiana, USA \\ ${ }^{2}$ Gastroenterology, LSU Health Sciences Center, Shreveport, Louisiana, USA \\ ${ }^{3}$ Obstetrics and Gynecology, LSU Health Sciences Center, Shreveport, Louisiana, USA \\ ${ }^{4}$ Neurology, LSU Health Sciences Center, Shreveport, Louisiana, USA \\ ${ }^{5}$ Nagoya City University Graduate School of Medical Sciences, Nagoya, Japan
}

\begin{abstract}
The Mucosal Addressin Cell Adhesion Molecule-1 (MAdCAM-1) is associated with active inflammatory bowel disease; however MAdCAM-1 expression in the pancreas has not been previously documented. This study investigated MAdCAM-1 expression during cerulein-induced pancreatitis, and examined MAdCAM-1 expression, regulation and function in cytokine-treated pancreatic endothelial cells. Acute pancreatitis was induced by serial injections of cerulein over 10h, at which point tissue samples were collected. Pancreas endothelial cells (PMEC) were prepared from $H$ $2 \mathrm{~Kb}$-tsA58 (Immortomouse) mice. MAdCAM-1 expression was examined by immunoblotting after cytokine (TNF- $\alpha$, IL- $\beta$ or IFN- $\gamma$ ) stimulation. $2^{\text {nd }}$ messages regulating MAdCAM-1 were studied by adding pharmacological blockers prior to cytokines. MAdCAM-1 dependent lymphocyte adhesion was monitored using $\alpha 4 \beta 7$-integrin expressing lymphocytes. In cerulein-pancreatitis, MAdCAM-1 was upregulated by $10 \mathrm{~h}$, and closely correlated with histopathology. In PMEC, only TNF- $\alpha$ induced MAdCAM-1 dose $(0-20 \mathrm{ng} / \mathrm{ml})$ and time $(>12 \mathrm{~h}-48 \mathrm{~h})$ dependently. MAdCAM-1 expression was PKC, tyrosine kinase, p38 MAPK, and NF- $\mathrm{BB}-\mathrm{PARP}$ dependent. PMEC-lymphocyte adhesion was increased by TNF- $\alpha$, and significantly reduced by MAdCAM-1 antibody. MAdCAM- 1 is induced in the inflamed pancreas, and in TNF- $\alpha$ stimulated PMEC, and may represent a novel determinant of pancreatic-lymphocyte recruitment in inflammation. PMEC cells might provide a useful system to study mechanisms related to both acute and chronic pancreatitis.
\end{abstract}

Keywords: Pancreatitis, inflammation, cytokine.

\section{INTRODUCTION}

Acute pancreatitis (AP) is a disease with very high morbidity and high mortality (up to $20-30 \%$ in severe AP) with no specific therapy beyond palliative supportive treatment [1]. The severe necrotizing form of AP is considered to be a multi-stage disease, where the pathological events beginning at the acinar cell level, are paralleled by an exaggerated local but also systemic inflammatory response [2]. As a result, AP is frequently associated with remote injury to the lung that presents clinically as 'adult respiratory distress' or 'ARDS' $[3,4]$. Generally, AP is thought to result from the premature and/or excessive intra-acinar zymogen activation by several stimuli including an exaggerated and inappropriate secretion of toxic oxidants, enzymes and bacteriostatic/bactericidal factors by several classes of activated leukocytes [5]. After the initiation of acinar cell injury, inflammatory cells penetrate the pancreatic interstitium first by adhering to activated endothelium, and then extravasating into the tissues. Leukocytes adhere to endothelial cells during inflammation after exposure to a variety of chemical mediators and inflammatory cytokines released at sites of tissue damage. These

*Address correspondence to this author at the Molecular and Cellular Physiology, LSU Health Sciences Center, 1501 Kings Highway, Shreveport, LA 71130-3932, USA; Tel: 318-675-4151; Fax: 503-907-7543;

E-mail: jalexa@1suhsc.edu trigger the synthesis, mobilization and presentation of endothelial adhesion molecules [6]. In pancreatitis, the adhesion molecule ICAM-1 and chemokines, such as macrophage inflammatory peptide $1-\alpha \quad($ MIP1- $\alpha)$ and interleukin-8 (IL-8), are implicated in the neutrophil sequestration which occurs in the pancreas and the lungs in $\mathrm{AP}$, and appear to be important initial events in triggering AP [7-9]. In AP, cytokines and chemokines produced both locally within the pancreas and remotely (by macrophages in the peritoneum) provoke inflammatory responses through autacrine and paracrine regulatory mechanisms [10]. Several factors including tumor necrosis factor (TNF)- $\alpha$, IL-1, IL-8 control the severity of AP, and are correlated with clinical outcomes $[6,9,11,12]$. Some recent reports show an improved survival and attenuation of local and remote inflammatory changes in experimental models of AP following cytokine blockade $[13,14]$. However, while cytokines may be involved in AP, many different mechanisms could be involved. Therefore the exact pathway(s) through which these events contribute to the injury in AP remain unclear. In the current study we investigated how cytokines regulate the expression and function of the endothelial adhesion molecule 'MAdCAM-1' using a novel pancreas endothelial cell line. MAdCAM expression was also examined in an in vivo model of AP. These data suggest that cytokine induced expression of endothelial adhesion molecules (like MAdCAM1) in the pancreas may contribute to AP etiology, and that anti-adhesive or anti-cytokine therapies may be effective 
cytokine therapies may be effective avenues of treatment for AP.

\section{MATERIALS AND METHODS}

\section{Isolation of Pancreatic Endothelial Cells}

PMEC were isolated by using a modification of the technique reported by Jat et al. [25]. Mice, homozygous for a temperature-sensitive SV40 large T antigen (ImmortoMice; CBA/ca X C57Bl/10 hybrid; Charles River Laboratories, Wilmington, MA), were sacrificed by ketamine/xylazine overdose. Pancreas tissues were minced into small $(1 \mathrm{~mm})$ fragments in $1 \mathrm{ml}$ HBSS and digested in $0.25 \%$ type IV collagenase (Sigma Chemical Co., St. Louis, MO), at $4^{\circ} \mathrm{C}$ for $24 \mathrm{~h}$. Tissues were then immersed in a $37^{\circ} \mathrm{C}$ water bath for 1 $\mathrm{h}$ with intermittent shaking every 15 minutes. Vessel fragments were filtered across $100 \mu \mathrm{m}$ nylon mesh into a $50 \mathrm{ml}$ polypropylene centrifuge tube; microvessel fragments were captured on $20 \mu \mathrm{m}$ nylon screening. The filtered fractions were centrifuged at $1500 \mathrm{RPM}$ for $5 \mathrm{~min}$ at $10^{\circ} \mathrm{C}$. The supernatant was discarded, and the pellet was resuspended in MEM D-valine (Promo Cell, Heidelberg, Germany) supplemented with $10 \%$ fetal bovine serum, 2-mM L-glutamine, nonessential amino acids, MEM-vitamin solution and $1 \%$ antibiotic/antimycotic (Life Technologies, Inc., Rockville, MD). Cells were plated onto $25-\mathrm{cm}^{2}$ flasks (coated previously with $2 \%$ gelatin). Twenty-four hours later, the medium was discarded, and fresh 10\% DMEM containing 10 units $/ \mathrm{ml}$ IFN- $\gamma$ (Pierce Biotechnology Inc., Rockford, IL) was added. The addition of IFN- $\gamma$ was used to activate the MHC H-2Kb class I promoter, to induce the expression of large $\mathrm{T}$ antigen in 'Immortomouse' derived cell cultures [25]. Primary endothelial cultures were incubated at $33^{\circ} \mathrm{C}$ in $7.5 \%$ carbon dioxide, and media replaced twice weekly. Primary isolates were grown to confluence ( $10-20$ days), and medium was changed to MEM D-valine supplemented with $10 \%$ fetal bovine serum, 2-mM L-glutamine, non-essential amino acids, MEM-vitamin solution and $1 \%$ antibiotic/antimycotic also containing 10 units $/ \mathrm{ml}$ IFN- $\gamma$. Cells were grown on gelatin-coated T-25 flasks or gelatin-coated glass coverslips. After cultures reached confluence, they were maintained in this medium and sub-cultured weekly.

\section{Immunofluorescent Staining for VCAM-1 and DiI-Ac- LDL in PMEC}

At confluence, PMEC cultured on gelatin-coated glass coverslips were fixed in $95 \%$ ethanol for 30 minutes (on ice), and extracted in $100 \%$ acetone (for 1 minute) and air dried. Primary antibody for mouse anti-VCAM-1 (1: 250) (Endogen, Rockford, IL) in $0.1 \%$ milk powder in PBS was incubated with coverslips for 1 hour at $37^{\circ} \mathrm{C}$. Coverslips were washed with $0.1 \%$ milk/PBS solution for 5 minutes 3 times each. Secondary antibody (donkey-anti-mouse FITC diluted 1: 200 in $0.1 \%$ milk/PBS, Jackson Immunoresearch Laboratories., West grove, PA,) was incubated at $37^{\circ} \mathrm{C}$ for 1 hour. Coverslips were washed with $0.1 \%$ milk/PBS solution for 5 minutes (3 times), mounted in glycerol-PBS and sealed with nail polish.

The receptor mediated endocytosis of 1,1'-dioctadecyl1,3,3,3'-tetramethylindocarbocyanine perchlorate acetylated low-density lipoprotein (DiI-Ac-LDL) (Biomedical Technologies Inc., Stoughton, MA) was investigated in PMEC.
DiI-Ac-LDL $(10 \mu \mathrm{g} / \mathrm{ml})$ was added to the culture dish and was incubated for 4 hours. The dishes were washed three times in medium and were visualized immediately by fluorescence microscopy.

\section{Treatment of PMEC Cells with Cytokines}

To determine how PMEC respond to cytokines, confluent monolayers were treated with either TNF- $\alpha$, IL- $1 \beta$ or IFN- $\gamma$ in complete cell culture medium for different amounts of time (up to 48 hours), and at different concentrations (IL-1 $\beta$ $0-100 \mathrm{ng} / \mathrm{ml}$; IFN- $\gamma, 0-5000 \mathrm{U} / \mathrm{ml}$ ). Bioactivity of the 3 cytokines used in this study were confirmed in parallel adhesion molecule expression studies (data not shown). In some experiments, PMEC cells were pre-treated with pharmacological blockers for $1 \mathrm{~h}$ prior to addition of cytokines to investigate which $2^{\text {nd }}$ messages mediate cytokine induced MAdCAM-1 protein transcription/translation in PMEC. Similar PMEC stimulation was also carried out in lymphocyte adhesion studies. In adhesion studies, stimulating cytokines were removed in prior to addition of labeled lymphocytes.

\section{Western Analysis of Cell Lysates}

Western blotting was performed as previously described. Briefly, protein samples (75 $\mu \mathrm{g}$ each) were separated on $7.5 \%$ SDS-PAGE gels and were electro-blotted to nitrocellulose membranes. Equal protein content per lane was confirmed by reversibly staining the nitrocellulose blots with Ponceau Red-S dye (Sigma, St. Louis, MO) allowing examination of the $43 \mathrm{kD}$ actin band. Images were recorded using an HPscanjet 3970 scanner (HP instruments), and stored electronically before removing Ponceau during blocking step (5\% milk in PBS). Membranes were incubated with $1^{\circ}$ antimouse MAdCAM-1 monoclonal antibody $(10 \mu \mathrm{g} / \mathrm{ml}$ MECA367; Pharmingen, San Diego, CA). Goat anti-rat horseradish peroxidase-conjugated $2^{\circ}$ antibody (Sigma-Aldrich, St. Louis, MO) was added at a 1: 2,000 dilution. Membranes were developed by enhanced chemiluminescence (Amersham, La Jolla, CA). MAdCAM-1 staining intensity was measured by scanning the $58-$ to $60-\mathrm{kDa}$ band and performing image densitometry (Image J, NIH, Bethesda, MD). The data are expressed as a percentage of the level of MAdCAM1 density induced by TNF- $\alpha$ (set at $100 \%$ ). All experiments were performed in triplicate.

\section{TK-1 Lymphocyte Adhesion Assay}

Mouse lymphocytes (Mouse CD8+ T cell lymphoma tyrosine kinase (TK)-1 cells) that constitutively express integrin $\alpha 4 \beta 7$ were a generous donation by Dr. Eugene Butcher (Stanford Univ., Stanford, CA) [26]. These cells were cultured in RPMI medium supplemented with $10 \%$ FCS, 2 mM L-glutamine, and $0.05 \mathrm{mM} 2$-mercaptoethanol. TK-1 cells, suspended in culture medium, were fluorescence labeled by incubating $2 \times 10^{6}$ cells $/ \mathrm{ml}$ with $0.02 \mathrm{mg}$ fluorescein diacetate (FDA) per $\mathrm{ml}$ (Sigma-Aldrich, St. Louis, $\mathrm{MO})$ at $37^{\circ} \mathrm{C}$ for $15 \mathrm{~min}$. The cells were washed twice with ice-cold HBSS, to remove unincorporated fluorescence and suspended in HBSS. The lymphocyte cell line used in this assay expresses high levels of the $\alpha 4 \beta 7$ integrin, which can interact with multiple ligands including mucosal addressin-1 (MAdCAM-1), but also VCAM-1, L-selectin and fibronectin $[27,28]$. In this system, TNF- $\alpha$ stimulated TK- 1 adhesion to endothelial cells was at least 50\% MAdCAM-1 mediated 
[28]. PMEC were grown in 96-well plates as described. PMEC were activated with TNF- $\alpha(20 \mathrm{ng} / \mathrm{ml})$ for $24 \mathrm{~h}$. TNF$\alpha$ treated PMEC were washed three times with media. Labeled TK-1 cells were added to the PMEC at a 10: 1 lymphocyte to endothelial cell ratio and allowed to bind for 15 min under static conditions. At the end of the incubation period, the supernatant was removed and the monolayers were washed twice with HBSS. These plates were read on a Fluoroskan Ascent (Labsystems, Helsinki, Finland) set for excitation at $485 \mathrm{~nm}$, emission at $515 \mathrm{~nm}$. Blank wells $(0 \%$ TK-1 cells) were run as controls that did not contain labeled TK-1 cells. Adhesion was calculated as the amount of bound cell fluorescent signal as a percent of the total applied cells. In each protocol, experiments were performed at least in triplicate.

\section{2nd Messages Involved in TNF- $\alpha$-Induced MAdCAM-1}

G-132 was purchased from Biomol (Plymouth Meeting, PA) [29]. GPI-6150, a poly-ADP-ribose polymerase (PARP) inhibitor, was obtained from Guilford Pharmaceuticals (Baltimore, MD). Genistein was purchased from Sigma (St. Louis, MO). PD-98059, SB-202190, GO-6976, and KT-5823 were all purchased from Calbiochem (La Jolla, CA). To examine the second messengers involved in the induction of MAdCAM-1 expression by TNF- $\alpha$, PMEC were pretreated with either proteosome inhibitor (MG-132), poly-ADP ribose polymerase inhibitor (GPI-6150), tyrosine kinase inhibitor (genistein), mitogen/extracellular signal-regulated kinase (MEK)-1 inhibitor (PD-98059), a p38 MAPK inhibitor (SB-202190), classical PKC antagonist (GO6976), a PKG inhibitor (KT-5823) or a cytochrome P450 inhibitor (itraconazole, Ortho biotech Products, Raritan, NJ). These drugs were added to PMEC 1 hour before stimulation with TNF- $\alpha$ to induce MAdCAM-1 protein expression.

\section{Cerulein Model of Pancreatitis}

C57BL/6J mice were purchased from Jackson Labs (Bar Harbor, Maine). Cerulein was purchased from Bachem, Inc. (Torrance, CA), and cerulein induced pancreatitis was induced as described by Ethridge et al. [32]. Briefly, mice (under ketamine/xylazine anesthesia) were intraperitoneally injected with cerulein $(50 \mu \mathrm{g} / \mathrm{kg}) 1 \mathrm{X}$ every hour for 8 hours. Mice were sacrificed 1 hour after the last cerulein injection. Pancreas tissue was frozen at $-20^{\circ} \mathrm{C}$ in OCT embedding compound and 10 um frozen sections stained for MAdCAM1 immunofluorescence. This study was reviewed and approved by the LSUHSC-Shreveport Animal Care and Use Committee.

\section{Statistical Analysis}

All values are expressed as mean $\pm \mathrm{SD}$. Data were analyzed using One-way Analysis of Variance (ANOVA) with Dunnett's post-testing. Probability $(\mathrm{P})$ values of $<0.05$ were considered significant.

\section{RESULTS}

\section{Pancreatic Endothelial Cell Line}

We established the pancreatic endothelial cell line 'PMEC' from 'Immortomouse' (H-2Kb-tsA58) mice in which all cells express the transgene for a temperaturesensitive SV40 large T antigen. Fig. (1A) shows a phasecontrast image of this cell line, which shows a uniform cob- blestone appearance. These cells also demonstrated endocytosis of DiI-AC-LDL (Fig 1B). These cells also positively

immunostained for m-VCAM-1 (Fig. 1C) and expressed MAdCAM-1 following TNF- $\alpha$ stimulation. These properties confirm that these cells have an endothelial origin. Histopathological staining showed that in passage 8 cultures there were up to $4.5 \%$ desmin-positive cells.
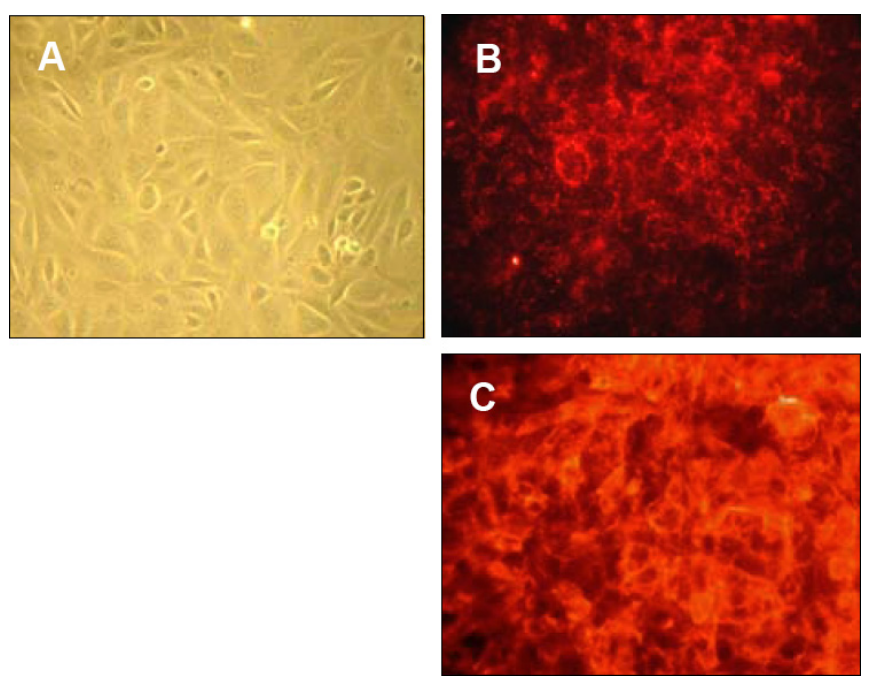

Fig. (1). (A) Phase contrast image of pancreatic microvessel endothelial cells (PMEC). (B) PMEC receptor mediated endocytosis of Dil-Ac-LDL. (C) PMEC VCAM-1 immunofluorescence. (200X magnification).

Additional rounds of subcultivation produced cultures which are free of these contaminants (confirmed by western blotting). Similarly, amylase reactivity was also found in early, but not in higher ( $>$ P13) passage cultures (also confirmed by western blotting using murine and human pancreas tissue as controls. Therefore, markers for stellate cells may be present in some early cultures, but are selected against, yielding a pure endothelial cell line.

\section{Analysis of MAdCAM-1 Expression by Pancreatic Endo- thelial Cells}

We next examined the expression of MAdCAM-1 protein in response to three major inflammatory cytokines, TNF- $\alpha$, IL-1 $\beta$, IFN- $\gamma$ (Pierce Biotechnology Inc., Rockford, IL). The expression of MAdCAM-1 protein was measured by western blotting using the MAdCAM-1 specific antibody, 'MECA367' mAb. We found that unlike VCAM-1 (see Fig. (1C)) MAdCAM-1 was not constitutively expressed on unstimulated PMEC, but was potently induced by TNF- $\alpha(20 \mathrm{ng} / \mathrm{ml}$; Fig. (2)). Interestingly, MAdCAM-1 was not expressed in response to treatment with either IL-1 $\beta$ (10 ng/ml; Fig. (2)) or IFN- $\gamma(1000 \mathrm{U} / \mathrm{ml}$; Fig. (2)). Bioactivity of IFN- $\gamma$ was confirmed by cell ELISA.

\section{TNF-a Stimulates MAdCAM-1 Expression Dose- and Time-Dependently}

In untreated PMEC cells, MAdCAM-1 was only faintly detected in western blots. Incubation of PMEC with TNF- $\alpha$ for $24 \mathrm{~h}$ caused a large and dose-dependent increase in MAdCAM-1 (Fig. 3A). MAdCAM-1 was significantly increased by TNF- $\alpha$, maximal MAdCAM-1 expression oc- 
curred at $20 \mathrm{ng} / \mathrm{mL}$. TNF- $\alpha(20 \mathrm{ng} / \mathrm{ml})$ for 8,24 or $48 \mathrm{~h}$ also caused a time-dependent increase in MAdCAM-1; maximal

\section{MAdCAM-1}
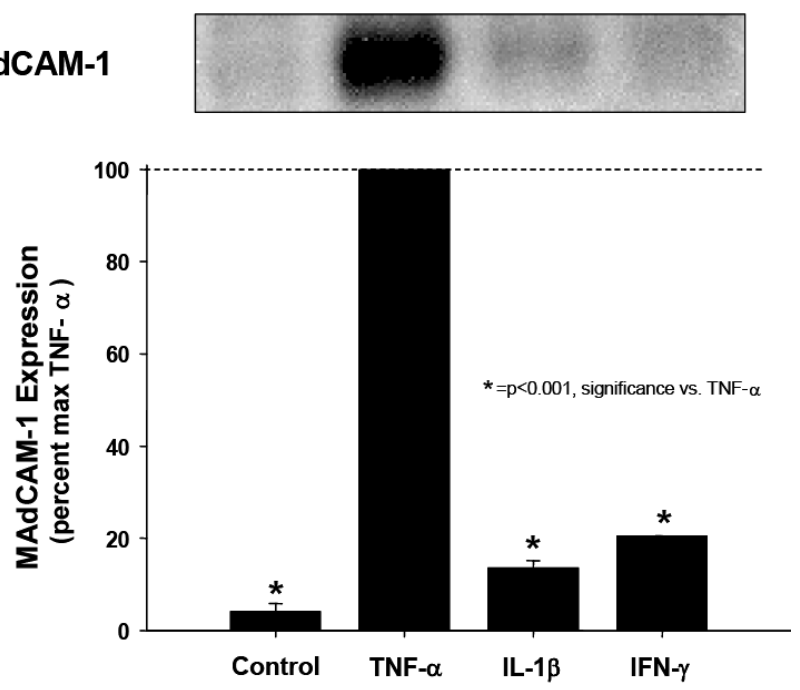

Fig. (2). Immunoblotting for MAdCAM-1 in PMEC. PMEC were incubated with TNF- $\alpha(20 \mathrm{ng} / \mathrm{ml})$, IL-1 $\beta \quad(10 \mathrm{ng} / \mathrm{ml})$ or IFN- $\gamma$ $(1000 \mathrm{U} / \mathrm{ml})$ for $24 \mathrm{~h}$. Immunoblotting of total cellular protein extracted from PMEC was performed. ${ }^{*} \mathrm{p}<0.001 v s$ TNF- $\alpha$.

MAdCAM-1 expression occurred at 48h (Fig. 4). Both Figs. $(3,4)$ show approximately a 10 -fold increase in MAdCAM-1 expression following TNF- $\alpha$ treatment (compared to untreated controls). On the other hand, MAdCAM-1 was not induced in PMEC by incubation for up to 24 hours with either IL- $1 \beta$ or IFN- $\gamma$ Fig. (3B)).

\section{Effect of Signal Transduction Blockers on MAdCAM-1 Expression}

To determine the cytoplasmic signals mediating TNF- $\alpha$ -

A

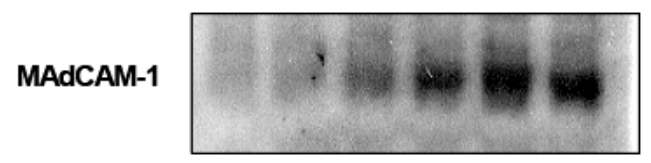

MAdCAM-1

IL-1 $\beta$ (ng/ml)
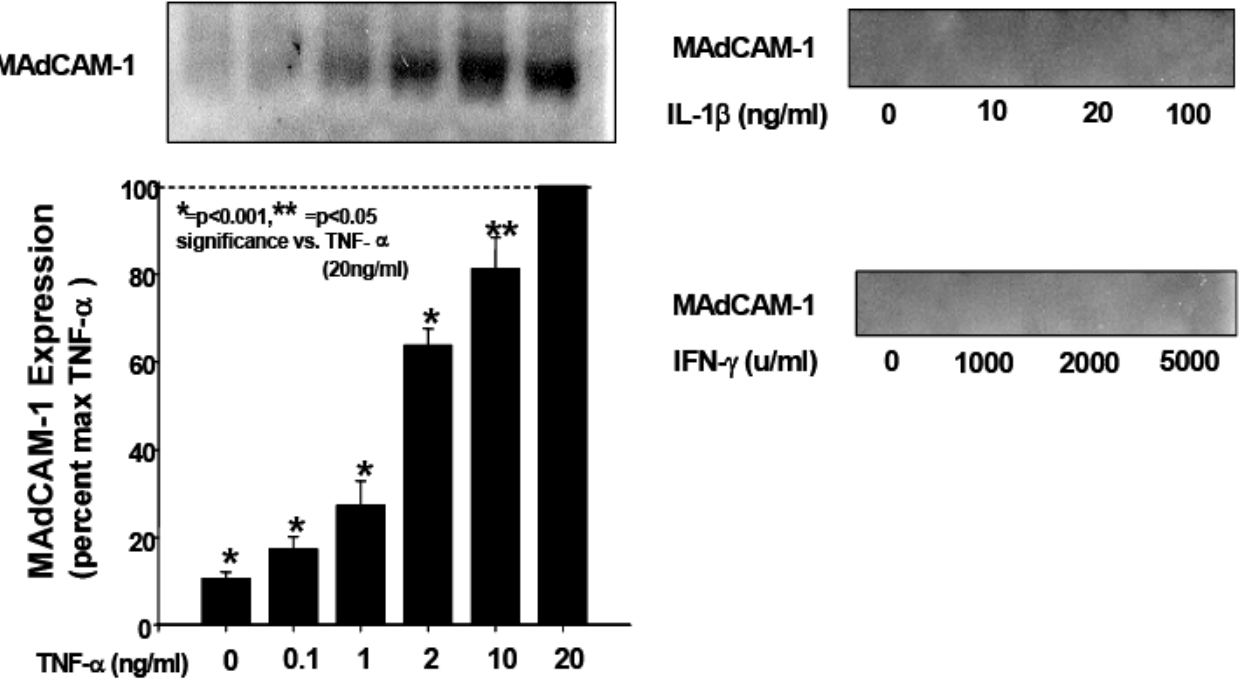

MAdCAM-1

IFN- $\gamma(\mathbf{u} / \mathbf{m l})$

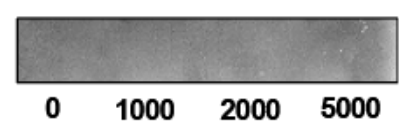

Fig. (3). (A) MAdCAM-1 Expression in PMEC is TNF- $\alpha$ concentration dependent. Confluent endothelial cells were incubated for $24 \mathrm{~h}$ with the concentration of mouse A. TNF- $\alpha$ indicated and levels of expression expressed as a fraction of the maximum (max. scan density obtained at 24 hours). (B) MAdCAM-1 is not induced by IL-1 $\beta$ or IFN- $\gamma$ at any concentration tested. 
model of pancreatitis in vivo. We observed visible differences in pancreatic structure between control tissues and those from mice receiving consecutive injections of cerulein

\section{MAdCAM-1}
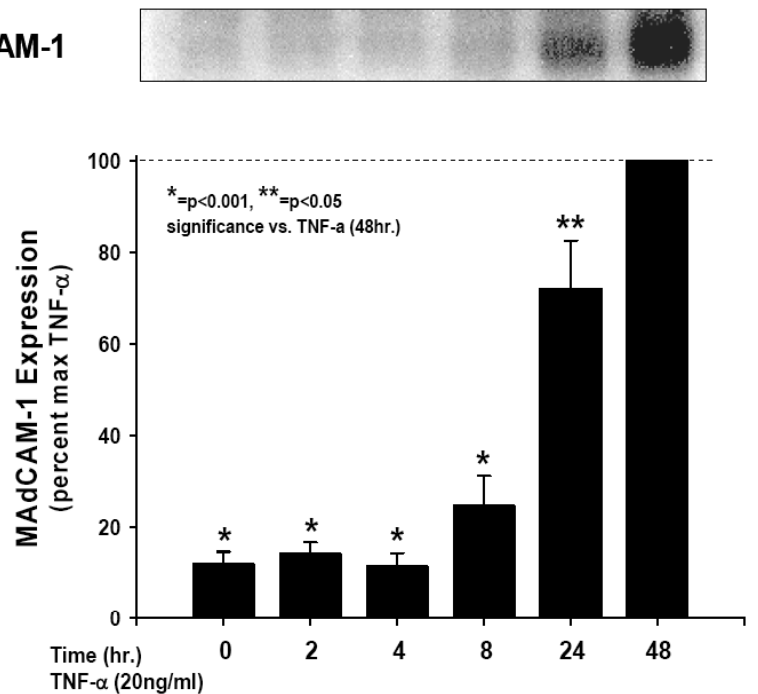

Fig. (4). Time-dependent TNF- $\alpha$-induced MAdCAM-1 expression. Confluent endothelia were incubated with $20 \mathrm{ng} / \mathrm{mL}$ TNF- $\alpha$ for the time periods indicated. Expression of MAdCAM-1 protein increased at 12, 24 and $48 \mathrm{~h}$. (Maximum expression [100\%] in this set of experiments was set as the scan density at 48 hours). In each graph, the $\mathrm{t}=0$ time point represents non-stimulated pancreatic endothelial cells. Each value represents the mean \pm s.e.; each group $(\mathrm{n}=3) . * \mathrm{P}<0.001, * * \mathrm{P}<0.05$ vs TNF- $\alpha$ treatment.

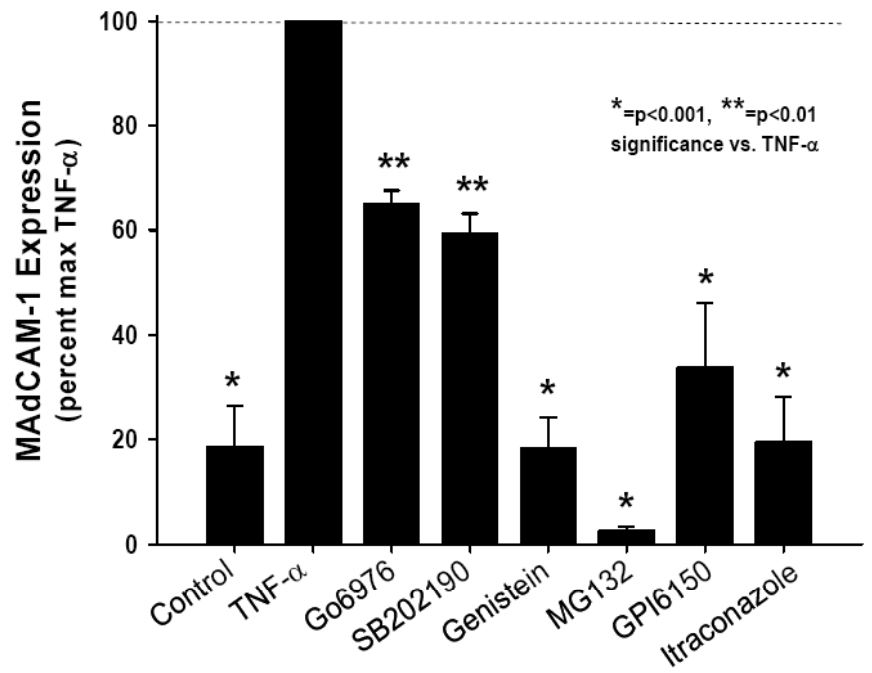

Fig. (5). Effect of signal transduction blockers on MAdCAM-1 Induction by TNF- $\alpha$ in PMEC. Cells were pretreated with Go 6976(100nM), SB-202190 $(10 \mu \mathrm{M})$, genistein $(30 \mu \mathrm{M})$, PD-98059 $(20 \mu \mathrm{M}), \mathrm{MG}-132(5 \mu \mathrm{M}), \mathrm{GPI}-6150(60 \mu \mathrm{M})$ or KT-5823 $(0.5 \mu \mathrm{M})$ and then exposed to TNF- $\alpha(20 \mathrm{ng} / \mathrm{ml})$ stimulation in the continued presence of inhibitors. MAdCAM-1 expression is significantly increased after TNF- $\alpha$. Go 6976, SB- 20219, genistein, MG-132 or GPI-6150 blocked the increase of MAdCAM-1 induced by TNF$\alpha .^{*}=\mathrm{p}<0.001,{ }^{*}=\mathrm{p}<0.01$, significance $v s$ TNF- $\alpha$. Values represent means $\pm \mathrm{SE} ; \mathrm{n}=3$ experiments in each group.
(Fig. 7). Cerulein treatment promoted cell swelling and detachment from their neighbors at foci of leukocyte infiltration; (control Fig. (7A) vs Fig. (7B) visualized by hematoxylin/eosin). The inset in Fig. (7B) shows a mass of infiltrated leukocytes obliterating other structures in the inflamed pancreas (arrow); this is in contrast to the inflamed but still structurally recognizable tissues seen in Fig. (7B). Similarly, MAdCAM-1 staining was not seen in control tissues, but was observed in cerulein treated pancreas tissue (Fig. 7C vs Fig. 7D).

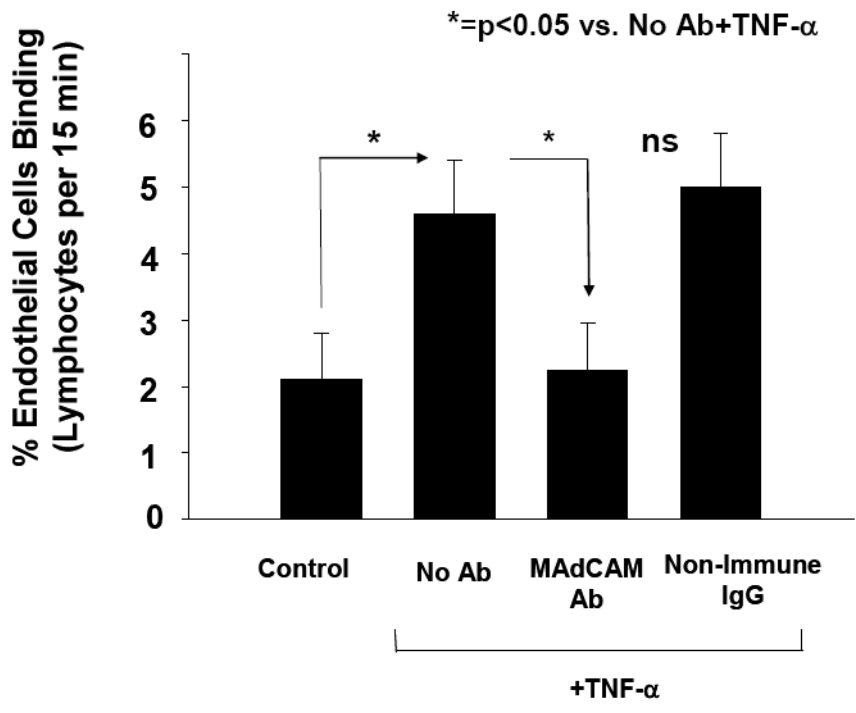

Fig. (6). TNF- $\alpha$ Induced TK-1 Adhesion to PMEC. TNF- $\alpha$ significantly increased TK-1-pancreas endothelial cell adhesion. This increased adhesion was significantly inhibited by pre-treatment with MECA-367 (mouse MAdCAM-1) Ab (10mg/ml), but not by the addition of an isotype matched pre-immune IgG (not significant). Each value represents the mean \pm s.e.; each group $(n=6) .{ }^{*} \mathrm{P}$ $<0.05$ vs TNF- $\alpha$ treatment.
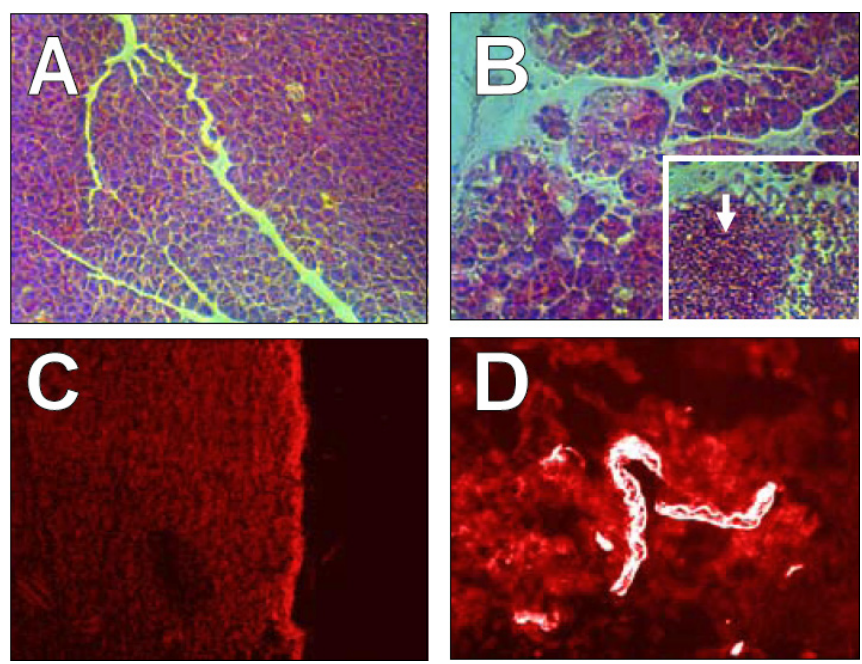

Fig. (7). Expression of MAdCAM-1 in experimental pancreatitis. $(\mathbf{A}, \mathbf{B})$ phase photos of normal and cerulein-induced AP; $(\mathbf{C}, \mathbf{D})$ show MAdCAM-1 immunostaining for control and ceruleininduced AP respectively (200X magnification).

\section{DISCUSSION}


In our present study, we created a pancreatic endothelial cell line using endothelial selective medium containing Dvaline with endothelial specific growth factors. It was reported that in D-valine supplemented media with endothelial specific growth factors, cultures are selected for endothelium and depleted of fibroblasts and other contaminating cell types [33, 34]. The mouse strain (H-2Kb-tsA58; Immortomouse) has been used extensively to generate several immortalized mouse cell lines for cell-based studies [35]. This mouse provides a source of nearly any selectable cell population, and avoids most of the limitations encountered when using immortalized agents including the sites of integration of genes into host genome and duplication of genes [25]. This cell model expresses a temperature sensitive $\mathrm{T}$ antigen and allows the elimination of T-antigen, its growth promoting activity and other phenotypic effects when the culture temperature is raised to $39^{\circ} \mathrm{C}$. Immortomouse large $\mathrm{T}$ antigen is under the control of IFN- $\gamma$. IFN- $\gamma$ can alter several endothelial characteristics, like adhesion molecule expression, growth and survival. Therefore, because of this possible problem, we usually maintained our cells at the permissive temperature $\left(33^{\circ} \mathrm{C}\right)$ and then cultured cells for 24 Hours at $37^{\circ} \mathrm{C}$ before performing experiments (which inactivates most of the temperature sensitive SV40 T-antigen). In addition to temperature treatment, we also removed IFN- $\gamma$ from the culture medium for approximately 24 hours before initiating experiments $[51,52]$.

Our PMEC formed cobblestone monolayers at confluence (Fig. 1A). These cells were all immunostained by antiVCAM-1 antibody (Fig. 1C) and showed positive metabolic uptake of DiI-AC-LDL (Fig. 1B). These results confirmed the identity of these cells as microvessel endothelial cells derived from the pancreas.

Late sepsis-related deaths resulting from infectious pancreatic necrosis are reduced by antibiotic treatment. Some early deaths may still occur because of severe remote multiorgan injury [38]. In AP, immune cells are the main triggers of the acute systemic inflammatory response that determines disease severity. However, the pathways through which the deleterious effects of pancreatic inflammation provoke distant organ injury are unclear. Activated pancreatic macrophages may release inflammatory cytokines (e.g., IL-1, IL-6 and TNF- $\alpha$ ) as a response to local tissue injury [39]. These cytokines would be anticipated to aggravate local pancreatitis, and systemically may increase capillary permeability, recruit leukocytes and stimulate their extravasation [40]. Another important activity of macrophages is the presentation of antigens to $\mathrm{T}$ lymphocytes. IL-1 $\beta$ also promotes the release of IL-2 from T lymphocytes to increase lymphocyte expansion and activation [39]. Therefore local inflammatory responses could produce significant and remote effects throughout the body. We showed that MAdCAM-1 was expressed on PMEC in response to TNF- $\alpha$ but not induced in response to IL-1 $\beta$ or IFN- $\gamma$ (Figs. 2-4). We therefore assumed that TNF- $\alpha$ might be the key cytokine leading to these forms of diffuse pancreatic injury.

Acute pancreatitis is an inflammatory disease, and its severity varies widely, based on several factors which determine the clinical 'grade' of pancreatitis. It is generally believed that one of the earliest events in development of AP is a premature intra-acinar release of digestive zymogens and metalloproteinases which when activated damages acinar cells and help trigger forms of remote tissue injury. This concept is supported by several studies suggesting that severity in pancreatitis reflects levels of acinar cell injury [41]. This injury includes inflammatory cell recruitment and activation, the release of inflammatory cytokines, oxidants and proteases. Leukocyte-endothelial cell adhesion, the earliest step in inflammation, precedes injury in several forms of chronic inflammation e.g. gastrointestinal inflammation [42]. However, although adhesion molecules must likely play a role in pancreatitis, there is no evidence supporting pancreatic endothelial expression of adhesion molecules, and how this might impact the course of pancreatitis as is reported in other organs. Frossard et al. showed that pancreatitis and pancreatitis-associated lung injury were remarkably decreased in mice deficient in CD40L compared with that in wild type [43] suggesting CD40-CD40L interactions. In another study, this group showed that ICAM-1 deficient mice show reduced pancreatitis severity and associated lung injury [7]. Importantly, neutrophil depletion also reduced pancreatitis severity and remote lung injury, events independent of ICAM-1 [7]. Demols et al. showed that T lymphocytes, particularly CD4+ T-cells, play a central role in cerulein pancreatitis. These results indicate that both neutrophils and lymphocytes contribute to pancreatitis [44].

MAdCAM-1 is expressed on high endothelial venules and mucosal vessels, where it guides lymphocyte traffic into Peyer's patches and the intestine [45]. MAdCAM-1 performs critical roles in several immune and inflammatory diseases like inflammatory bowel disease (IBD) through its ability to bind and retain $\beta 7$-integrin expressing lymphocytes within the gut, where they appear to drive inflammation in IBD [16]. In this study, we showed that MAdCAM-1 was expressed on the pancreatic endothelium in cerulein-induced pancreatitis (Fig. 7). The expression of MAdCAM-1 was increased in mouse pancreatic endothelial cells in vitro after TNF- $\alpha$ stimulation (Figs. 2-5).

MAdCAM-1 expression in the pancreas is somewhat unanticipated. MAdCAM-1 has been previously thought to be restricted to specialized microvascular endothelial cells lining venules (high endothelial venules) and in some cases inflamed cerebral endothelium [28]. Our results indicate that MAdCAM-1 expression on the pancreatic blood vessels might recruit lymphocytes to both aggravate local and remote multi-organ injury during AP.

Oshima et al. reported that TNF- $\alpha$ induced the expression of MAdCAM-1 on lymph node derived endothelium (SVEC4-10) and bEnd.3, a brain capillary endothelial cell line, two models for evaluating mechanisms of human IBD and cerebral inflammation [28]. Prior results suggest that TNF- $\alpha$-induced MAdCAM- 1 expression in the pancreas might also be controlled through tyrosine kinase, PKC, and perhaps PKG, MAPKs, and NF- $\kappa \mathrm{B}$, as has been reported for other endothelial adhesion molecules in colitis and IBD [17]. It is known that TNF- $\alpha$ receptors mobilize NF- $\kappa \mathrm{B}$ and activate several levels of protein kinases, resulting in the release and proteosomal degradation of $\mathrm{I} \kappa \mathrm{B}$ from the inert NF- $\kappa \mathrm{B}-$ I $\kappa \mathrm{B}$ complex $[23,46]$. The release of $\mathrm{I} \kappa \mathrm{B}$ permits the translocation of the activated p50/p65 NF- $\kappa \mathrm{B}$ complex to the nucleus [47]. Read et al. reported that MG-132, a proteosome of the inhibitor, prevented $\mathrm{I} \kappa \mathrm{B} \alpha$ degradation induced by 
TNF- $\alpha$ and nuclear accumulation of NF- $\kappa B$, efficiently inhibiting NF- $\mathrm{kB}$ function [48]. In our study, the expression of MAdCAM-1 was completely inhibited by MG-132, indicating that NF- $\mathrm{KB}$ helps to control MAdCAM-1 expression in PMEC. Recent studies show that NF- $\kappa B$ antagonist, (NF- $\kappa B$ antisense phosphorothioate oligonucleotide) and a $26 \mathrm{~S}$ proteosome inhibitor successfully attenuate inflammation in experimental colitis in vivo [49, 50]. Therefore antagonists to these signaling cascades might also provide important therapeutic strategy to limit forms of MAdCAM-1-dependent inflammation. Some prior reports have suggested that NF-kB activation is critically involved in the cerulein induced model of pancreatitis. For example, Steinle et al. have suggested that NF- $\mathrm{KB}$ activation represents an important and direct effect of cerulein on acinar cells, rather than an indirect effect mediated by cytokines derived from activated mononuclear cells [51]. We assume that activation of NF- $\mathrm{KB}$ is essential in the responses to cytokines in our model, with some responses not related to cytokines as well.

We also demonstrated that MAdCAM-1 transcription and translation are regulated through the PKC, PARP, p38MAPKs, TK, and NF- $\kappa$ B signal cascades. MEK-1 and PKG inhibitors did not influence MAdCAM-1 expression. The signal transduction pathways in TNF- $\alpha$-induced MAdCAM-1 expression are likely to differ somewhat among cell types in their sensitivity to PKC/MEK-1 inhibition. Interestingly, in previous reports, ERK1 inhibition did not block the upregulation of ICAM-1 in IL-1 $\beta$-treated cardiac myocytes and fibroblasts [52]. It has also been reported that p38 MAPK may be required for NF- $\mathrm{kB}$-dependent gene expression, and that inhibition of the p38 MAPK pathway prevented IL-1 $\beta$-induced ICAM and VCAM translation [49, 53]. Here we have found that the signals from PKC, PARP, p38MAPKs and TK might be upstream of NF- $\kappa B$ in the case of TNF- $\alpha$-induced pancreatic endothelial MAdCAM- 1 expression.

When organ systems are exposed to intense inflammatory stimuli (e.g., cytokines), the expression of several cell adhesion molecules (CAMs), (P-selectin, ICAM-1 and VCAM1), is often increased on the surface of the endothelium, and mediates a coordinated and sequential activation of leukocyte rolling, firm adhesion, and transendothelial diapedesis. It is known that ICAM-1 plays a significant role in leukocyte infiltration of the pancreas and that anti-ICAM-1 antibody therapy decreases acinar cell damage in experimental pancreatitis $[54,55]$. Also, Nerin et al. showed the therapeutic effectiveness of chimeric TNF antibody, infliximab [56]. In our study, TNF-stimulated PMEC bind TK-1 lymphocytes directly and is decreased by anti-MAdCAM-1 antibody. Our observations are consistent with lymphocyte recruitment to the pancreas in inflammation (e.g. acute pancreatitis) as being MAdCAM- $1 / \alpha 4 \beta 7$-integrin dependent suggesting that the MAdCAM-1/ $\alpha 4 \beta 7$ pair bond may initiate pancreatitis. Future in vivo and in vitro may determine if interference with this binding (possibly using humanized antibodies against $\alpha 4 \beta 7$ e.g. Antegren/Natalizumab) might be useful prophylactic/therapeutic modalities for the treatment of pancreatitis.

\section{ACKNOWLEDGEMENTS}

This work supported by NIH DK43785 AND THE Department of Gastroenterology and Hepatology of the Louisiana State University Health Sciences Center of Shreveport.

The authors who would like to acknowledge Ms. Shannon Wells for superior assistance in preparing this manuscript.

\section{REFERENCES}

[1] Rau B, Uhl W, Buchler MW, et al. Surgical treatment of infected necrosis. World J Surg 1997; 21: 155-161.

[2] Norman JG. New approaches to acute pancreatitis: role of inflammatory mediators. Digestion 1999; 60(Suppl 1): 57-60.

[3] Ranson JH, Turner JW, Roses DF, et al. Respiratory complications in acute pancreatitis. Ann Surg 1974; 179: 557-566.

[4] Ranson JH, Roses DF, Fink SD. Early respiratory insufficiency in acute pancreatitis. Ann Surg 1973; 178: 75-79.

[5] Hofbauer B, Saluja AK, Lerch MM, et al. Intra-acinar cell activation of trypsinogen during caerulein-induced pancreatitis in rats. Am J Physiol 1998; 275: G352-G362.

[6] Kingsnorth A. Role of cytokines and their inhibitors in acute pancreatitis. Gut 1997; 40: 1-4.

[7] Frossard JL, Saluja A, Bhagat L, et al. The role of intercellular adhesion molecule 1 and neutrophils in acute pancreatitis and pancreatitis-associated lung injury. Gastroenterology 1999; 116: 694701.

[8] Gerard C, Frossard JL, Bhatia M, et al. Targeted disruption of the beta-chemokine receptor CCR1 protects against pancreatitisassociated lung injury. J Clin Invest 1997; 100: 2022-2027.

[9] Gross V, Andreesen R, Leser HG, et al. Interleukin-8 and neutrophil activation in acute pancreatitis. Eur J Clin Invest 1992; 22: 200-203.

[10] Norman J. The role of cytokines in the pathogenesis of acute pancreatitis. Am J Surg 1998; 175: 76-83.

[11] Exley AR, Leese T, Holliday MP, et al. Endotoxaemia and serum tumour necrosis factor as prognostic markers in severe acute pancreatitis. Gut 1992; 33: 1126-1128.

[12] McKay CJ, Gallagher G, Brooks B, et al. Increased monocyte cytokine production in association with systemic complications in acute pancreatitis. Br J Surg 1996; 83: 919-923.

[13] Grewal HP, Mohey ED, Gabber L, et al. Amelioration of the physiologic and biochemical changes of acute pancreatitis using an anti-TNF-alpha polyclonal antibody. Am J Surg 1994; 167: 214218 .

[14] Norman JG, Fink GW, Messina J, et al. Timing of tumor necrosis factor antagonism is critical in determining outcome in murine lethal acute pancreatitis. Surgery 1996; 120: 515-521.

[15] Streeter PR, Berg EL, Rouse BT, et al. A tissue-specific endothelial cell molecule involved in lymphocyte homing. Nature 1988; 331: 41-46.

[16] Nakache M, Berg EL, Streeter PR, et al. The mucosal vascular addressin is a tissue-specific endothelial cell adhesion molecule for circulating lymphocytes. Nature 1989; 337: 179-181.

[17] Briskin M, Winsor-Hines D, Shyjan A, et al. Human mucosal addressin cell adhesion molecule-1 is preferentially expressed in intestinal tract and associated lymphoid tissue. Am J Pathol 1997; 151: $97-110$.

[18] Connor EM, Eppihimer MJ, Morise Z, et al. Expression of mucosal addressin cell adhesion molecule-1 (MAdCAM-1) in acute and chronic inflammation. J Leukoc Biol 1999; 65: 349-355.

[19] Hanninen A, Jaakkola I, Jalkanen S. Mucosal addressin is required for the development of diabetes in non-obese diabetic mice. J Immune 1998; 160: 6018-6025.

[20] Souza HS, Elia CC, Spencer J, et al. Expression of lymphocyteendothelial receptor-ligand pairs, alpha4beta7/MAdCAM-1 and OX40/OX40 ligand in the colon and jejunum of patients with inflammatory bowel disease. Gut 1999; 45: 856-863.

[21] Fong S, Jones S, Renz ME, et al. Mucosal addressin cell adhesion molecule-1 (MAdCAM-1). Its' binding motif for alpha 4 beta 7 and role in experimental colitis. Immunol Res 1997; 16: 299-311.

[22] Kato S, Hokari R, Matsuzaki K, et al. Amelioration of murine experimental colitis by inhibition of mucosal addressin cell adhesion molecule-1. J Pharmacol Exp Ther 2000; 295: 183-189.

[23] Collins T. Endothelial nuclear factor-kappa B and the initiation of the atherosclerotic lesion. Lab Invest 1993; 68: 499-508. 
[24] Collins T, Read MA, Neish AS, et al. Transcriptional regulation of endothelial cell adhesion molecules: NF-kappa B and cytokineinducible enhancers. FASEB J 1995; 9: 899-909.

[25] Jat PS, Noble MD, Ataliotis P, et al. Direct derivation of conditionally immortal cell lines from an $\mathrm{H}-2 \mathrm{~Kb}$-tsA58 transgenic mouse. Proc Natl Acad Sci USA 1991; 88: 5096-5100.

[26] Andrew DP, Berlin C, Honda S, et al. Distinct but overlapping epitopes are involved in alpha 4 beta 7 -mediated adhesion to vascular cell adhesion molecule-1, mucosal addressin-1, fibronectin, and lymphocyte aggregation. J Immunol 1994; 153: 3847-3861.

[27] Ruegg C, Postigo AA, Sikorski EE, et al. Role of integrin alpha 4 beta 7/alpha 4 beta $P$ in lymphocyte adherence to fibronectin and VCAM-1 and in homotypic cell clustering. J Cell Biol 1992; 117: 179-189.

[28] Oshima T, Pavlick KP, Laroux FS, et al. Regulation and distribution of MAdCAM-1 in endothelial cells in vitro. Am J Physiol Cell Physiol 2001; 281: C1096-C1105.

[29] Rock KL, Gramm C, Rothstein L, et al. Inhibitors of the proteasome block the degradation of most cell proteins and the generation of peptides presented on MHC class I molecules. Cell 1994; 78: 761-771.

[30] Alessi DR, Cuenda A, Cohen P, et al. PD 098059 is a specific inhibitor of the activation of mitogen-activated protein kinase kinase in vitro and in vivo. J Biol Chem 1995; 270: 27489-27494.

[31] Lee JC, Laydon JT, McDonnell PC, et al. A protein kinase involved in the regulation of inflammatory cytokine biosynthesis. Nature 1994; 372: 739-746.

[32] Ethridge RT, Ehlers RA, Hellmich MR, Rajaraman S, Evers BM. Acute pancreatitis results in induction of heat shock proteins 70 and 27 and heat shock factor-1. Pancreas 2000: 21: 248-256.

[33] Abbott NJ, Hughes CC, Revest PA, et al. Development and characterization of a rat brain capillary endothelial culture: towards an in vitro blood-brain barrier. J Cell Sci 1992; 103 ( Pt 1): 23-37.

[34] Picciano PT, Johnson B, Walenga RW, et al. Effects of D-valine on pulmonary artery endothelial cell morphology and function in cell culture. Exp Cell Res 1984; 151: 134-147.

[35] Whitehead RH, VanEeden PE, Noble MD, et al. Establishment of conditionally immortalized epithelial cell lines from both colon and small intestine of adult $\mathrm{H}-2 \mathrm{~Kb}$-tsA58 transgenic mice. Proc Natl Acad Sci USA 1993; 90: 587-591.

[36] Beynon HL, Haskard DO, Davies KA, et al. Combinations of low concentrations of cytokines and acute agonists synergize in increasing the permeability of endothelial monolayers. Clin Exp Immunol 1993; 91: 314-319.

[37] Groves RW, Ross EL, Barker JN, et al. Vascular cell adhesion molecule-1: expression in normal and diseased skin and regulation in vivo by interferon gamma. J Am Acad Dermatol 1993; 29: 6772.

[38] Lowham A, Lavelle J, Leese T. Mortality from acute pancreatitis. Late septic deaths can be avoided but some early deaths still occur. Int J Pancreatol 1999; 25: 103-106.

[39] Kusske AM, Rongione AJ, Reber HA. Cytokines and acute pancreatitis. Gastroenterology 1996; 110: 639-642.

[40] Rosario HS, Waldo SW, Becker SA, et al. Pancreatic trypsin increases matrix metalloproteinase-9 accumulation and activation during acute intestinal ischemia-reperfusion in the rat. Am J Pathol 2004; 164(5): 1707-16.

[41] Saluja AK, Steer MLP. Pathophysiology of pancreatitis. Role of cytokines and other mediators of inflammation. Digestion 1999; 60(Suppl 1): 27-33.

[42] Panes J, Granger DN. Leukocyte-endothelial cell interactions: molecular mechanisms and implications in gastrointestinal disease. Gastroenterology 1998; 114: 1066-1090.

[43] Frossard JL, Kwak B, Chanson M, et al. CD40 ligand-deficient mice are protected against cerulein-induced acute pancreatitis and pancreatitis-associated lung injury. Gastroenterology 2001; 121: 184-194.

[44] Demols A, Le Moine O, Desalle F, et al. CD4(+)T cells play an important role in acute experimental pancreatitis in mice. Gastroenterology 2000; 118(3): 582-590.

[45] Butcher EC, Picker LJ. Lymphocyte homing and homeostasis. Science 1996; 272: 60-66.

[46] Weber C, Negrescu E, Erl W, et al. Inhibitors of protein tyrosine kinase suppress TNF-stimulated induction of endothelial cell adhesion molecules. J Immunol 1995; 155: 445-451.

[47] Ghosh S, May MJ, Kopp EB. NF-kappa B and Rel proteins: evolutionarily conserved mediators of immune responses. Annu Rev Immunol 1998; 16: 225-260.

[48] Read MA, Whitley MZ, Williams AJ, et al. NF-kappa B and I kappa B alpha: an inducible regulatory system in endothelial activation. J Exp Med 1994; 179: 503-512.

[49] Conner EM, Brand S, Davis JM, et al. Proteasome inhibition attenuates nitric oxide synthase expression, VCAM-1 transcription and the development of chronic colitis. J Pharmacol Exp Ther 1997; 282: 1615-1622.

[50] Murano M, Maemura K, Hirata I, et al. Therapeutic effect of intracolonically administered nuclear factor kappa B (p65) antisense oligonucleotide on mouse dextran sulphate sodium (DSS)-induced colitis. Clin Exp Immunol 2000; 120: 51-58.

[51] Steinle AU, Weidenbach H, Wagner M, et al. NF-kappaB/Rel activation in cerulein pancreatitis. Gastroenterology 1999; 116: 420-430.

[52] Kacimi R, Karliner JS, Koudssi F, et al. Expression and regulation of adhesion molecules in cardiac cells by cytokines: response to acute hypoxia. Circ Res 1998; 82: 576-586.

[53] Carter AB, Knudtson KL, Monick MM, et al. The p38 mitogenactivated protein kinase is required for NF-kappaB-dependent gene expression. The role of TATA-binding protein (TBP). J Biol Chem 1999; 274: 30858-30863.

[54] Rau B, Paszkowski A, Esber S, et al. Anti-ICAM-1 antibody modulates late onset of acinar cell apoptosis and early necrosis in taurocholate-induced experimental acute pancreatitis. Pancreas 2001; 23(1): 80-88.

[55] Werner J, Z'graggen K, Fernandez-del CC, et al. Specific therapy for local and systemic complications of acute pancreatitis with monoclonal antibodies against ICAM-1. Ann Surg 1999; 229(6): 834-40; discussion 841-842.

[56] Oruc N, Ozutemiz AO, Yukselen V, et al. Infliximab: a new therapeutic agent in acute pancreatitis? Pancreas 2004; 28(1): e1-8. 